Farrokhlagha Heidari, Nurullah Mansourzadeh. (2014). Grammar ConsciousnessRaising Activities and Iranian EFL Learners' Attitudes toward English Language. Journal of Education and Learning. Vol.8 (3) pp. 257-272.

\title{
Grammar Consciousness-Raising Activities and Iranian EFL Learners' Attitudes toward English Language
}

\author{
Farrokhlagha Heidari $^{*}$ \\ University of Sistan and Baluchestan, Iran \\ Nurullah Mansourzadeh $^{* *}$ \\ University of Sistan and Baluchestan, Iran
}

\begin{abstract}
The first purpose of this study was to investigate the effect of consciousness-raising (C-R) activities on learning grammatical structures by Iranian EFL learners. The second one was to investigate the effect of gender through C-R activities and tasks. Finally, this study wanted to investigate the Iranian students' attitudes toward learning English prior to and after applying the C-R activities. An attitude questionnaire was use to investigate the participants' attitudes toward learning English before and after applying C-R activities. Data analysis indicated that using C-R activities in is significantly more effective than the traditional approaches. Regarding gender, male outperformed females. Therefore, it is recommended that other teachers consider C-R activities as useful options in teaching other aspects of language. Based on the statistics and findings, Iranian students' attitudes toward learning English language were not much different prior to and after applying C-R activities.
\end{abstract}

Keywords: Grammar, Consciousness-Raising Activities, EFL, Attitude

\footnotetext{
* Dr. Farrokhlagha Heidari, University of Sistan and Baluchestan, Iran

E-mail: F. Heidari 51@yahoo.com

** Prof.Nurullah Mansourzadeh, University of Sistan and Baluchestan, Iran

E-mail: N.Mansourzadeh60@gmail.com
} 


\section{Introduction \\ Background of the Study}

The term grammar has been interpreted in different ways, often causing confusion in the realm of language teaching. These misconceptions lie mostly in the view that grammar is regularly seen just as a set of arbitrary rules about fixed structures in teaching different rules of language such as verb paradigms and rules about linguistic forms. Grammar is unmistakably much more than this (Crivos \& Luchini, 2012). English language grammar is one of those skills and aspects that consist of system of a language that must be mastered by English language learners. Grammar supplies learners with opportunities to associate these forms with appropriate meanings and the teaching procedures are designed to teach learners to produce a range of grammatical sentences. The aim of teaching grammar is to introduce acceptable sentences. We can think of these sentences as grammatical frames or as the system of rules governing the conventional arrangement and relationship of words in a sentence (Brown, 2007). However, low levels of attainment associated with this type of teaching, plus an everdeveloping awareness of the complexity of language which brought about by corpus linguistics, have pointed out problems with deductive instructions. Rules as given by teachers and textbooks are often seen, at best, as helpful but over-simplistic generalizations; and at worst, as fallacious distortions of real language which contribute little or nothing to learners' productive mastery of linguistic forms (Ranalli, 2001). What is attitude? How does it influence the process of language learning? How can learners' positive or negative attitudes facilitate or hinder the process of language acquisition? De Bot (2005, p.72) claimed that "teachers, learners and researchers will all agree that a high motivation and a positive attitude towards a second language and its community help the process of second language learning". Researchers in the fields of psychology and education, especially language learning, consider several definitions of attitude which mention different meanings and uses from different contexts and perspectives (Alhmali, 2007). Based on the theory of planned behaviour, Montano and Kasprzyk (2008) state that attitude is determined by the individuals' beliefs about outcomes or attributes of performing the behaviour (behavioural beliefs), weighted by evaluations of those outcomes or attributes. Thus, a person who holds strong beliefs and considers those values related to the foreign language positively, accepts the process of language learning with open arms. Conversely, a person who holds strong negative beliefs about the language which s/he is learning, will have a weak performance in the course of langue learning and there is no hope for the process of assimilation with the community speakers of that target language. Fasold (1984) claimed that attitudes towards a language are often mirrored in the attitudes towards the members of that speech community that it may arouse either hostility or friendliness among learners. According to Prodromou (1992), language attitude is an important and influencing concept because it plays a key role in the process of language learning and teaching. A successful learner is the person who possesses positive attitudes towards the target language and considers its learning as a valuable activity that helps him/her to achieve some objectives in future. Everyone agrees that positive attitudes towards a language, its culture and people can help to achieve a certain goal but the question is how they could be measured.

\section{Statement of the Problem and Purpose of the Study}

One of the most difficult questions that every teacher has in his/her mind when entering the classroom is this: should I teach grammatical points to my students? How should I present the grammatical points to them? So many questions like these may come to the mind of any English teacher (Ellis, 2002). Larsen-Freeman (1995) claims that though grammar is acquired naturally, it does not necessarily mean that it should not be taught. Teaching can enhance the internalizing of grammar, and help speed up the process. The two important techniques of teaching grammar are C-R approach and the traditional approach. In C-R approach, learners discover grammatical rules and notice the structure by themselves and also they are taught implicitly. These types of activities are noticed by learners. In contrast, conventional tasks are more controlled or directed by the teacher and are taught explicitly, where the formulated information about forms and their functions are presented directly. However, in this research we want to investigative the effectiveness of C-R approach in presenting grammar items to Iranian beginner learners. In spite of the importance of grammar and also the significance of communication and discovery-based approaches in language teaching and learning, few studies nationwide have been conducted to highlight this important aspect of language pedagogy. Moreover, few studies investigated the effectiveness of C-R versus traditional work. The purpose of the present study is to explore the effect of $\mathrm{C}-\mathrm{R}$ activities as a new pedagogical approach on learning English grammar (simple present tense in this case) in Iranian EFL context. It also investigates whether there is any significant difference between Iranian male and female learners in learning the simple present tense regarding applying $\mathrm{C}-\mathrm{R}$ activities. The learners' attitudes prior to and after applying $\mathrm{C}-\mathrm{R}$ activities have also been investigated in this study. 


\section{Research Questions}

1. Is there any significant difference between Iranian guidance school EFL learners learning grammatical structures through C-R activities and traditional methods?

2. Is there any significant difference between Iranian male and female guidance school EFL learners learning grammatical structures through C-R activities and tasks?

3. Is there any significant difference between Iranian guidance school EFL learners' attitudes toward learning English language prior to and after applying C-R activities and tasks?

\section{Review of Literature \\ Grammars: The Controversial Aspect of Language}

From the days of Grammar Translation Method(GTM), the deductive approaches to language learning, in which grammar rules are explicitly presented to students and followed by practices and drills employing those rules, have been the bread and butter of language teaching around the world and still being dominant in many course contents, curriculum design and self-study grammar books (Fortune, 1992). There have been different interpretations of the term grammar among specialists, and these have resulted in emerging confusing ideas and viewpoints as far as this language aspect is concerned. These misunderstandings manifest themselves in the debates that grammar is traditionally seen as a set of arbitrary and fixed paradigms related to linguistic forms. Absolutely grammar has more to do than this simplistic interpretation (Crivos \& Luchini, 2012).

\section{The Birth of New Approaches}

Based on Thornbury (1999), although presentation-practice- production (P-P-P) has enjoyed, and still enjoys today a great popularity among teachers, teacher trainers and curriculum developers, it has come under heavy criticism recently. The basis of much of this criticism is the notion that an important gap exists between teaching and learning. Students may be able to demonstrate a good grasp of a particular form during classroom activities but later, when once again operating under the pressures of real-time communication, they no longer exhibit the same control. Theories for the origin of this gap centre on the idea of the internal syllabus, the natural order of acquisition of linguistic structures which people must go through when learning a language. P-P-P is seen as a clumsy attempt to ignore or contravene this natural order. Learners cannot be taught structures they are not ready to acquire, so it begs the question: should teachers even try? Another major flaw in P-P-P, some claim, is its excessive emphasis on productive practice procedures. Asking students to use new grammar immediately may not only be unnecessary but also counterproductive, in that, it may distract attention away from the brain work involved in understanding and restructuring of the learner's interlanguage. Rather than production, teachers should aim only at drawing learners' attention to important features of the form under study. In other words, C-R activities should replace the old approaches in teaching different aspects of any language especially grammar features (Celce-Murcia, 1991).

\section{The History of GTM and C-R Approaches}

Based on Richards and Rodgers (1986), the GTM has its origins in the late 1700s. However, the influence of the approach on English Language Teaching (ELT) can be traced back to a period of approximately hundred years, from the 1840 s to the 1940 s, albeit it was heavily criticized as early as the 1880 s. It is the rule rather than the exception that ideas about language teaching and learning do not replace each other overnight, but have a tendency to coexist for some time and often the future method takes up elements of interest from the previous method. English was taught in the same way as the classical languages Greek and Latin, but of course English as part of the European syllabuses was not accepted before the1890s. According to Richards and Rodgers (1986, p. 5), the GTM is “... a method for which there is no theory." Nonetheless, there are some typical characteristics of the GTM, some of which have survived to this day.

\section{C-R Activities}

When we talk about c-r activities and tasks, they can be very different. In fact by c-r activities we mean an attempt to help our pupils to concentrate on some pieces of language unconsciously. So, highlighting, bolding, use of colours, use of different kinds of technologies, underlining, etc can be classified as different kinds of c-r activities and tasks.

\section{Language Attitude}

In addition to the intellectual perspective, the nature of language learning has psychological and social aspects and depends mainly on the learners' motivation and attitude to learn the target 
language by heart (Padwick, 2010). Gardner and Lambert (1972) have concluded that the ability of the students to master a second language is not only influenced by the mental competence or, language skills, but also by the students' attitudes, beliefs and perceptions towards the target language they are exposed to. They also advocated that attitude concept could enhance the process of language learning, influencing the nature of student's behaviours and beliefs towards the other language, its culture and community, and this will identify their tendency to acquire that language successfully. Baker (1992) proposed a comprehensive theoretical model, focusing on the importance of conducting attitudinal research in the field of language learning. He states that in the life of language learning, attitudes to that language appear to be important in language restoration, preservation, decay or death. Recently, De Bot (2005) asserts that language teachers, researchers and students should acknowledge that high motivation and positive attitude of students facilitate second language learning. Thus, if a learner does not have interest and tendency in acquiring the target language to communicate with others, this learner will possess a negative attitude and will not be motivated and enthusiastic in language acquisition. Therefore, learners' attitudes as crucial and effective inside factors could be incorporated in language learning and teaching milieu because they may influence students' performance in acquiring the target language either badly or successfully.

\section{Previous Studies on C-R Activities and Attitude}

Fotos and Ellis (1991) compared the effects of direct C-R by means of grammar explanation and indirect consciousness-raising by means of C-R tasks on Japanese learner's ability to judge the grammaticality of sentences involving dative alteration. They found that both methods of C-R resulted in significant gains in understanding the target language structures. Fotos (1993) conducted an experimental research to investigate the amount of learner noticing produced by two types of grammar $\mathrm{C}-\mathrm{R}$ treatments, teacher-fronted grammar lessons and interactive, grammar problem-solving tasks. Involving 160 Japanese college students of English, she designed her research by dividing the subjects into three different treatment groups, which were taught indirect object placement, adverb placement, and relative clause usage in communicative input. The findings revealed that the two types of grammar $\mathrm{C}-\mathrm{R}$ activities and tasks are effective in promoting significant level of noticing the target language structures in subsequent communicative input. Another study investigating the effectiveness of C-R was carried out by Yip (1994). Mohamed (2004) found that indirect C-R was more effective than direct consciousness-raising when applied to high intermediate ESL learners from mixed L1 background but not to low intermediate learners, suggesting that the proficiency of learners can determine the effectiveness of C-R. As for the C-R tasks (which can be deductive and inductive), Mohamed (2004) examines learners' perspectives of the effectiveness of such tasks. The findings indicated that learners have no strong preference for a particular type of task over the other. He viewed the tasks to be useful in assisting them to learn new knowledge about language. The findings suggest that $\mathrm{C}-\mathrm{R}$ tasks (both deductive and deductive) are effective learning tool and can therefore be used to raise learners' awareness of linguistic forms. Sugiharto (2006) investigated Indonesian students' ability in understanding the simple present tense rules through C-R activities and tasks, which often pose a problem for the students. Using a grammatical judgment test, Sugiharto compared the results from students' pre-and post-tests, and found that students' performance was significantly better on the posttest. This study indicated that $\mathrm{C}-\mathrm{R}$ is effective in helping students develop their explicit knowledge of the simple present tense especially in the problematic areas such as the third person singular. For instance, Shams (2008) conducted a study attempting to investigate Iranian EFL students' attitudes, motivation and anxiety towards the learning of English. The findings underlined that the students had affirmative attitudes and high enthusiasm towards English. This study also highlighted that most of them showed positive attitudes towards English language and its learning which, in turn, emphasized the value of English language efficiency in the daily life. Kara (2009) stated that attitudes towards learning besides opinions and beliefs have an obvious influence on students' behaviours and consequently on their performance in the long term of language acquisition. The findings of a study by Al-Tamimi and Shuib (2009) on Petroleum Engineering students' motivation and attitudes towards learning English language and teachers' creativity in applying new approaches and methods revealed that they had positive attitudes towards the use of English in the Yemeni social and educational contexts. They also showed affirmative attitude towards the culture of the English speaking world. AlZahrani (2008) conducted a study to determine the attitudes of Saudi students towards English. The statistical analysis revealed that there was not any clear difference among the three years in their attitudes towards Learning English language as the descriptive statistics showed that the respondents in the three years had the same level of attitude. A few Iranian researchers have examined the type of motivation and its orientation along with the attitudes of the learners towards learning English and found positive results. To give some examples, Vaezi's (2008) study revealed that Iranian students had 
very high motivation and positive attitudes towards learning English and they were more instrumentally motivated. Shirbagi's (2010) study showed that Iranian EFL students had a very positive attitude towards learning English language. In conclusion, teaching grammatical structures (in this case simple present tense) through C-R activities and tasks and evaluation of students' attitudes in Iran have received limited attention and few researches have been done practically. In this regard, the current study is an attempt to shed more light on discovery and creativity-based approaches such as C-R in Iranian learners' context and investigating their attitudes towards learning English through applying innovative and leraner-centerd approaches to fill the aforementioned gaps.

\section{Method \\ Participants}

One hundred male and female students from two different guidance schools in Zahedan, Iran, participated in the study. The participants were all native speakers of Persian language with an age range between 12 and 13, and all of them were in grade three of guidance school. 53\% of the participants were females and $47 \%$ were males. They were divided into two groups, 54 students in control group and 51 in experimental group. The experimental group was taught using C-R activities and tasks and the control group was taught based on practice and traditional approaches such as grammar translation method and P-P-P approach. In order to obtain unbiased results the researcher was instructor of all the participants of the study. The sampling process was based on convenience, due to availability reasons.

\section{Iranian Guidance Schools}

Guidance schools refer to secondary schools in Iranian system of education. It is necessary for Iranian children to pass this stage to promote other stages of education. The students studying in these schools are between ten to thirteen years old. English language is taught as a foreign language in Iranian context and there is a very little exposure to natural acquisition of language. So, it is very important for English language as teachers to provide some opportunities for students to learn the English language as easy as possible

\section{Data Gathering Instruments}

The instruments employed in this study were as follows: (a) English Beginner Proficiency Test- (proficiency test), (b) Teacher made Grammar Test (pre-test \& post-test) (c) An attitude questionnaire.

\section{English Test - Beginner (proficiency test)}

In order to make certain that all the learners were at the same level of language proficiency, English Beginner Proficiency Test was administered at the very beginning of the experiment. The test contains 100 multiple choice items related to different aspects of English language such as prepositions, regular and irregular verbs, vocabulary, English simple present and past tenses and reading comprehension. The participants were given enough time to answer the questions.

In order to estimate how reliable the use of the proficiency test is, the researcher administered the test to a pilot group of thirty students in Imam Hossein (As) guidance school. They were studying at the grade three like the participants of the present study. The KR-21 formula was used for the computation of the internal consistency of the test. The reliability index for the English Beginner Proficiency Test in this study was found to be 0.73 , which is considered a positive and acceptable reliability.

\section{Teacher- made Grammar Test}

A teacher-made grammar tests was used as the pre and post-test of this study which aimed to determine the level the participants' grammar knowledge on the simple present tense. The test consisted of 33 multiple choice items mainly constructed on the basis of the grammar points of students' text book. The grammatical structure of the book included: simple tense, its negative form and the question form of this tense. The reliability of pre-test and post-test was calculated using the (KR-21) formula and turned out to be 0.71 and 0.87 respectively which is acceptable index of reliability.

\section{An Attitude Questionnaire}

The third measuring instrument of this study was an attitude questionnaire which focused on the Iranian EFL students' attitudes towards learning English language prior to and after applying C-R and tasks. In fact, the purpose of using such a questionnaire was to evaluate the participants' attitudes 
prior to and after applying a specific approach such as C-R activities and tasks. The items were taken from Attitude and Motivation Test Battery (AMTB) designed by Gardner (1985). It was translated from English into Persian by the researcher and to investigate the validity of the questionnaire items, the questionnaire was given to three specialists and experts in TEFL, chosen from the teaching staff of University of Sistan and Baluchestan. Their comments were taken into consideration and they advocated that the items of the questionnaire are valid to investigate the research objectives. A pilot study was conducted to measure the reliability level of the questionnaire items. To do so, 30 students were randomly selected from the target population. These students did not take part in the actual study. They were required to present their personal information based on the Likert scale of the questionnaire items. An analysis of item reliability was determined through the reliability coefficient test. The acceptable value of Cronbach Alpha was 0.87 which shows acceptable consistency of reliability. This shows that the questionnaire items were completely appropriate for research goals. The value of Cornbach's Alpha regarding the behavioral aspect is 0.73 , the cognitive aspect obtained 0.77 , and the Cronbach's Alpha value of the emotional aspect is 0.67 . On the whole, there were 45 items concerning language attitudes towards learning English language in terms of: behavioural, cognitive, and emotional aspects of attitude. The items were put in a 5-point Likert scale from Level 1: Strongly Disagree to Level 5: Strongly Agree.

\section{Results}

In order to make sure that all the participants are at the same level of language proficiency, an English Beginner Proficiency Test was administered at the beginning of the study to the both groups. After gathering the data, the descriptive statistics was run by SPSS program. The descriptive statistics of proficiency test for both groups are shown in Table1.

Table 1. Descriptive statistics for proficiency test of Experimental and Control groups

\begin{tabular}{cccccc} 
Groups & Num. & Min. & Max. & Mean & Std. Deviation \\
\hline Experimental & 51 & 42 & 93 & 76.14 & 14.62 \\
Control & 54 & 39 & 95 & 77.35 & 15.47 \\
\hline
\end{tabular}

Based on Table 1, for experimental group, the mean score was 76.14 and the SD was 14.62. While for the control group, the mean score was 77.35 and the SD was 15.47. Since the means cannot show the actual difference between the groups, an Independent Sample T-test was run as shown in Table 2 .

Table 2. Independent sample T-test: experimental group proficiency test vs. control group proficiency

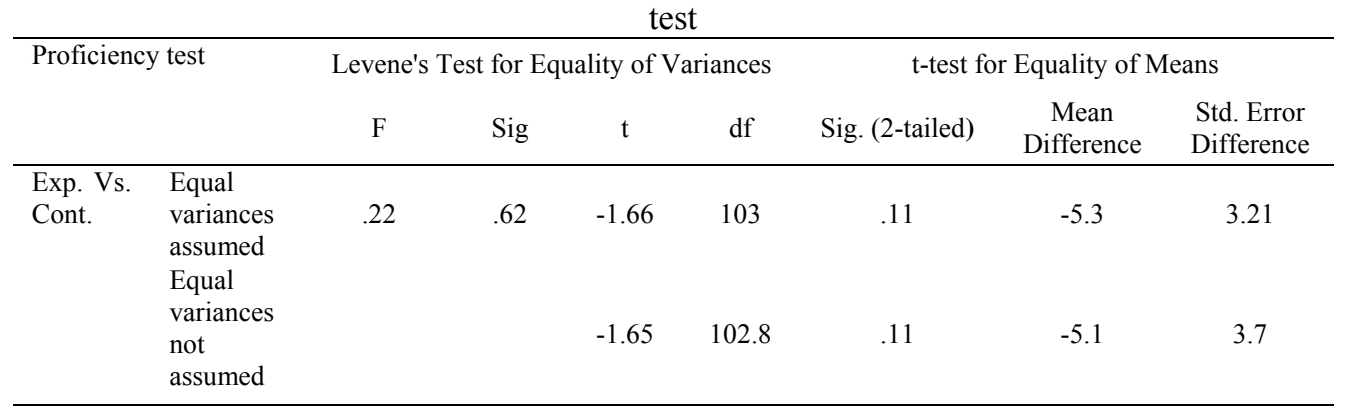

\section{Exp=experimental, Cont $=$ control}

As Table. 2 displays, there was no statistical difference between groups, $t(103)=-1.65, p<$ 0.05. As a result, no significant difference was detected between the learners' mean scores in the proficiency test within the experimental and control groups; therefore, the participants of both groups were homogeneous.In order to test the first null hypothesis, a series of independent samples t-tests were run using SPSS software. Before testing the first null hypothesis, normal distribution and internal reliability of both tests were investigated and calculated. 
Table 3. Descriptive Statistics for pre Test

\begin{tabular}{|c|c|c|c|c|c|c|c|c|c|}
\hline & \multirow{2}{*}{$\begin{array}{c}\mathrm{N} \\
\text { Statistic }\end{array}$} & \multirow{2}{*}{$\begin{array}{c}\text { Min. } \\
\text { Statistic }\end{array}$} & \multirow{2}{*}{$\begin{array}{c}\text { Max. } \\
\text { Statistic }\end{array}$} & \multirow{2}{*}{$\begin{array}{c}\text { Mean } \\
\text { Statistic }\end{array}$} & \multirow{2}{*}{$\begin{array}{c}\text { Std. Deviation } \\
\text { Statistic }\end{array}$} & \multicolumn{2}{|c|}{ Skewedness } & \multicolumn{2}{|c|}{ Kurtosis } \\
\hline & & & & & & Statistic & Std. Error & Statistic & Std. Error \\
\hline Pre-test & 105 & 3.00 & 24.00 & 10.1905 & 4.46804 & .808 & .236 & .395 & .467 \\
\hline Valid N (listwise) & 105 & & & & & & & & \\
\hline
\end{tabular}

Table 4. Descriptive Statistics for post Test

\begin{tabular}{|c|c|c|c|c|c|c|c|c|c|}
\hline & $\begin{array}{c}\mathrm{N} \\
\text { Statistic }\end{array}$ & $\begin{array}{c}\text { Min. } \\
\text { Statistic }\end{array}$ & $\begin{array}{c}\text { Max. } \\
\text { Statistic }\end{array}$ & $\begin{array}{c}\text { Mean } \\
\text { Statistic }\end{array}$ & $\begin{array}{c}\text { Std. Deviation } \\
\text { Statistic }\end{array}$ & $\begin{array}{r}\text { Skew } \\
\text { Statistic }\end{array}$ & $\begin{array}{l}\text { vedness } \\
\text { Std. Error }\end{array}$ & $\begin{array}{r}\mathrm{Ku} \\
\text { Statistic }\end{array}$ & $\begin{array}{l}\text { rtosis } \\
\text { Std. Error }\end{array}$ \\
\hline post-test & 105 & 7.00 & 33.00 & 18.6667 & 7.10318 & .170 & .236 & -.9087 & .467 \\
\hline Valid N (listwise) & 105 & & & & & & & & \\
\hline
\end{tabular}

According to Tables 3 and 4, both pre-test and post-test have normal distributions, as the kurtosis and skewedness statistics are between -1 and +1 which is an indicator of normal distribution. Moreover, to have a graphical representation of the distribution of the data, Figures 1 and 2 were drawn. As shown in these Figures, they have a bell-shaped curve which indicates the normal distribution.
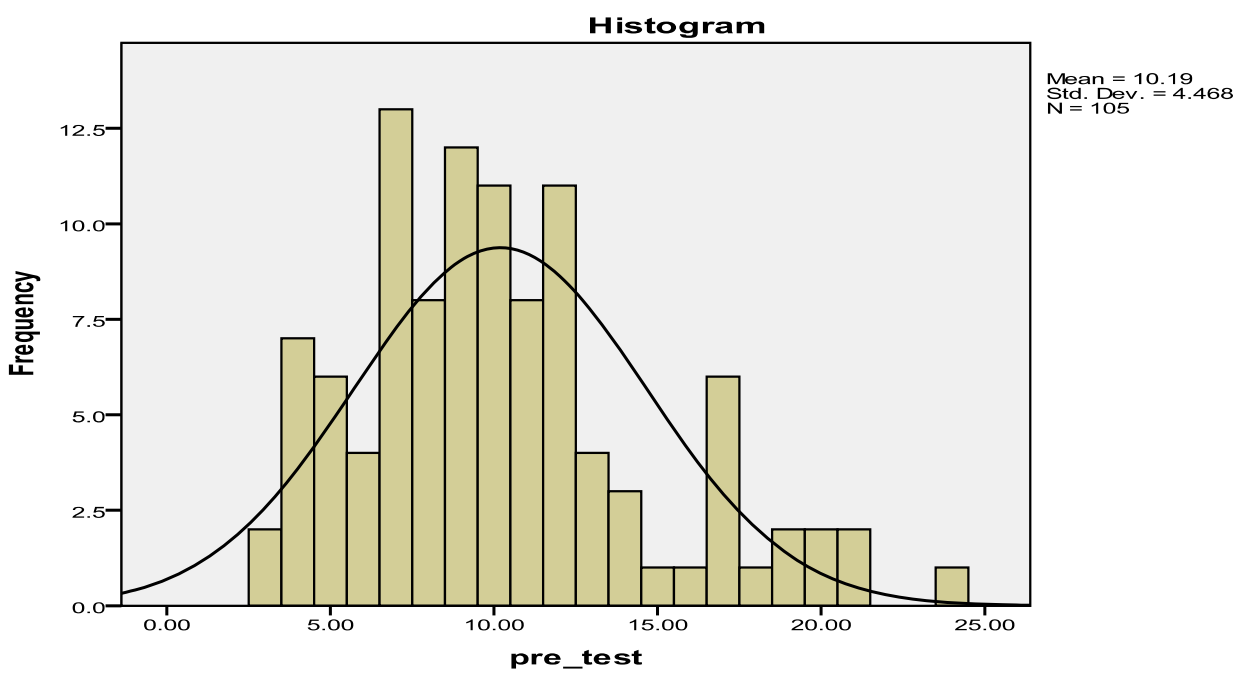

Figure 1. Normal distribution curve of the pre-test

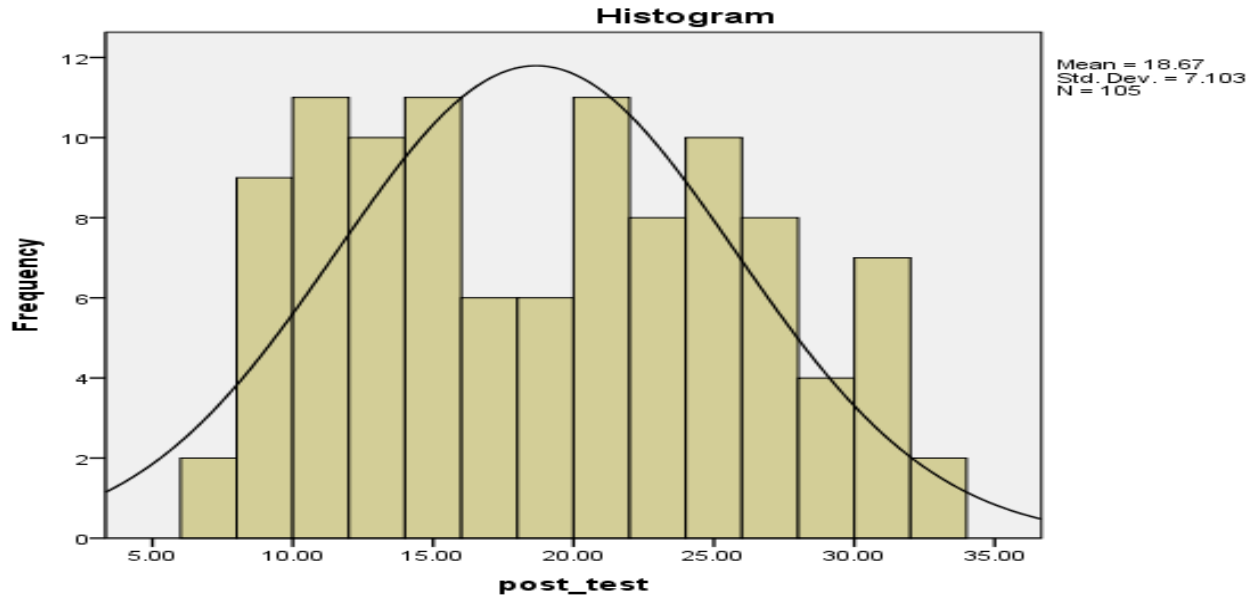

Figure 2. Normal distribution curve of the post-test 
Table 5. The Reliability Index for pre-test and post-test

\begin{tabular}{cccc} 
& Mean & Variance & KR-21 \\
\hline Pre-test & 10.19 & 19.90 & 0.71 \\
Post-test & 18.66 & 50.41 & 0.87 \\
\hline
\end{tabular}

To examine the reliability of the pre-test and post-test, the Kuder-Richardson Formula, (KR21), was used as indicated in Table 5. It is used to show the internal consistency of the items. In order to have a reliable test, KR-21 should be above .70. According to Table 5, both tests had acceptable reliability. Returning to the first research hypothesis, first an independent samples t-test was run to examine whether the two groups were homogeneous before treatment. The results show that both control and experimental groups are at the same level of grammatical achievement, and if there is any significant improvement in the performance of the experimental group, it is due to treatment not other outside factors. For this purpose, an independent sample T- test was run on the pre-test to check the homogeneity of the control and experimental groups before treatment.

Table 6. Group Statistics for pre-test

\begin{tabular}{lccccc}
\hline & group & $\mathrm{N}$ & Mean & $\begin{array}{c}\text { Std. } \\
\text { Deviation }\end{array}$ & Std. Error Mean \\
\hline \multirow{2}{*}{ pre-test } & control & 54 & 10.25 & 4.67 & .63 \\
& experimental & 51 & 10.11 & 4.28 & .59 \\
\hline
\end{tabular}

As can be seen in Table 6, the mean of the control group is 10.25 and its SD is 4.67 and that of the experimental group is 10.11 while its SD is 4.28 . Based on these findings, there is a very nuance difference between the two groups. In this study, we considered two experimental groups as one group and two control groups as one group.

Table 7. Independent Sample T-test for Equality of Means

\begin{tabular}{ccccccccc}
\hline & & & \multicolumn{3}{c}{$\begin{array}{c}\text { Levene's Test for } \\
\text { Equality of Variances }\end{array}$} & & \multicolumn{3}{c}{ t-test for Equality of Means } \\
& & F & Sig. & t & df & Sig. (2-tailed) & Mean Difference \\
\hline \multirow{2}{*}{ pre-test } & Equal variances assumed & .312 & .578 & .162 & 103 & .872 & .14161 \\
& Equal variances not assumed & & & & .162 & 102.909 & .872 & .14161 \\
\hline
\end{tabular}

However, to examine it statistically, an independent sample T-test was run as shown in Table 7. First, based on the Levene's test of equality of variances, appropriate $t$ was selected. As can be seen in Table 4.7, there is no statistically significant difference between experimental and control groups prior to treatment $(\mathrm{t}=.16, \mathrm{p}>.05, \mathrm{df}=103)$. This proved the homogeneity of the two groups.

Now, to examine whether treatment affected the grammatical achievement of the Iranian guidance school EFL learners, another independent sample T-test was used. The mean scores of the control and experimental groups for post-test are shown in Table 8.

Table 8. Group Statistics for post-test

\begin{tabular}{cccccc}
\hline & group & N & Mean & Std. Deviation & Std. Error Mean \\
\hline \multirow{2}{*}{ Post-test } & control & 54 & 16.62 & 6.01 & .81 \\
& experimental & 51 & 20.82 & 7.57 & 1.06 \\
\hline
\end{tabular}

As shown in Table 4.8, the mean of the experimental group $\mathrm{M}=20.82$ and its SD is 7.57 while that of that of the control group $\mathrm{M}=16.62$ with the $\mathrm{SD}$ of 7.57 . Based on these obtained results, the 
experimental group had a better performance on the post-test of the simple present tense and this refers to the effect of C-R activities and tasks on learning grammatical structures.

Table 9. Independent Samples Test for Post -test of experimental and control groups

\begin{tabular}{lccccccc}
\hline & & \multicolumn{3}{c}{ Levene's Test for Equality of Variances } & \multicolumn{3}{c}{ t-test for Equality of Means } \\
& & $\mathrm{F}$ & $\mathrm{Sig}$ & $\mathrm{t}$ & $\mathrm{df}$ & Sig.(2-tailed) & Mean Difference \\
\hline \multirow{2}{*}{ Post-test } & Equal variances assumed & 5.254 & .024 & -3.151 & 103 & .002 & -4.19390 \\
& Equal variances not assumed & & & -3.130 & 95.400 & .002 & -4.19390 \\
\hline
\end{tabular}

To check whether this difference is statistically significant, based on Table 49, an independent sample T-test was run. After selecting appropriate $t$ based on Levene's test for equality of variances, the results showed that there was a statistically significant difference between control and experimental groups $(\mathrm{t}=-3.13, \mathrm{p}<.05, \mathrm{df}=103)$. It can be said that experimental group outperformed the control group regarding their grammar scores. Therefore, the first null hypothesis is rejected. In order to test the second research hypothesis, an independent samples t-test was run. Like the previous section, first we should be aware of the homogeneity of the male and female students in two experimental groups. The results show that both males and females are at the same level of grammatical achievement, and if there is any significant improvement in the performance of these two experimental groups, it is due to treatment not other outside factors. For this purpose, an independent sample T-test was run on the pretest to check the homogeneity of the males and females before applying the treatment.

Table 10. Descriptive Statistics (Homogeneity of Males and Females in both Experimental Groups)

\begin{tabular}{cccccc}
\hline & group & $\mathrm{N}$ & Mean & Std. Deviation & Std. Error Mean \\
\hline \multirow{2}{*}{ Pre-test } & male & 28 & 9.67 & 4.18 & .79 \\
& female & 23 & 10.65 & 4.43 & .92 \\
\hline
\end{tabular}

As shown in Table 10, there is no statistically significant difference between the mean of the male $\mathrm{M}=9.67, \mathrm{SD}=4.18$ and female $10.65, \mathrm{SD}=4.43$ Iranian guidance school EFL learners $(\mathrm{t}=-.80$, $\mathrm{p}>.05, \mathrm{df}=49$ ).

Table 11. Equality of means for both experimental groups (Males and Females)

\begin{tabular}{|c|c|c|c|c|c|c|}
\hline & & \multicolumn{2}{|c|}{$\begin{array}{c}\text { Levene's Test for Equality of } \\
\text { Variances }\end{array}$} & \multicolumn{3}{|c|}{ t-test for Equality of Means } \\
\hline & & $\mathrm{F}$ & Sig. & $\mathrm{t}$ & df & Sig.(2-tailed) \\
\hline \multirow{2}{*}{ Pre-test } & Equal variances assumed & .035 & .853 & -.805 & 49 & .425 \\
\hline & Equal variances not assumed & & & -.800 & 45.900 & .428 \\
\hline
\end{tabular}

The means of the two groups on the grammar post-test were compared through another T-test. As Table 11 shows, the obtained $\mathrm{p}$ value $(\mathrm{p}=.05)$ confirmed the equality of variances and $\mathrm{t}(49)=-.80$, $\mathrm{p}<.05$ suggested that the mean differences of 0.98 is not significant. These results show that males and females are at the same level of grammatical proficiency prior to treatment. Now to consider whether gender affects learning grammatical structures through C-R activities and tasks, again, another independent sample t-test was run as was shown in Table 12.

Table 12. Group Statistics for post-test of both Experimental Groups (Males and Females)

\begin{tabular}{cccccc}
\hline & group & $\mathrm{N}$ & Mean & $\begin{array}{c}\text { Std. } \\
\text { Deviation }\end{array}$ & $\begin{array}{c}\text { Std. Error } \\
\text { Mean }\end{array}$ \\
\hline \multirow{2}{*}{ Pre-test } & male & 28 & 24.50 & 6.86 & 1.29 \\
& female & 23 & 16.34 & 5.86 & 1.22 \\
\hline
\end{tabular}


As can be seen in Table 12, the mean of the male students $M=24.50$ which is higher than that of the female students $M=16.34$. As the mean difference of both groups is 8.16 which is a significant difference therefore, the null hypothesis can be safely rejected. This indicates that $\mathrm{C}-\mathrm{R}$ activates and tasks were more effective in developing learners' knowledge of grammar than traditional approaches.

Table 13. Equality of means for both experimental groups (Males and Females)

\begin{tabular}{cccccccc}
\hline & & \multicolumn{3}{c}{$\begin{array}{c}\text { Levene's Test for } \\
\text { Equality of }\end{array}$} & \multicolumn{2}{c}{ t-test for Equality of Means } \\
& & Variances & & & \\
& $\mathrm{F}$ & Sig. & $\mathrm{t}$ & $\mathrm{df}$ & Sig. (2-tailed) \\
\hline \multirow{2}{*}{ Post-test } & Equal variances assumed & .350 & .557 & 4.503 & 49 & .000 \\
& Equal variances not assumed & & & 4.573 & 48.905 & .000 \\
\hline
\end{tabular}

To examine the significance of this difference, an independent sample T-test was run and it indicated in Table 4.13, there was statistically significant difference between the grammatical achievement of the male and female learners $(\mathrm{t}=4.50, \mathrm{p}<.05, \mathrm{df}=49)$. As the male students had a higher mean, it can be said that male students who learned grammatical structures through $\mathrm{C}-\mathrm{R}$ activities and tasks, had a better performance on grammar tests of the simple present tense than female students who also learned the same grammatical structures through C-R activities and tasks. Therefore, the second null hypothesis was rejected.

Table 14. Reliability Value of Cronbach's $\alpha$ Regarding Different Aspects of Foreign Language Attitude

\begin{tabular}{ccc}
\hline Aspects of Attitude & No. of Items & Cronbach's Alpha Value \\
\hline Behavioral aspect & 15 & 0.73 \\
Cognitive Aspect & 15 & 0.77 \\
Emotional Aspect & 15 & 0.67 \\
General Attitude towards English & 45 & 0.87 \\
\hline
\end{tabular}

In order to be sure about the reliability of the questionnaire, the Cronbach's $\alpha$ was utilized for measuring the internal consistency of the three aspects. As can be seen in the Table 14, Cronbach's $\alpha$ for all aspects of attitude is acceptable. Therefore, the questionnaire is ready for further inferential analysis. In order to answer the third research question, an attitude questionnaire was distributed to the experimental groups before and after the treatment. Before answering this research question, descriptive statistics and internal reliability of the scale and its subscales of the questionnaire were examined.

Table 15. Descriptive Statistics for Normality of Attitude and its Subscales

\begin{tabular}{ccccccccccc}
\hline & $\mathrm{N}$ & Min. & Max. & Mean & \multicolumn{2}{c}{ Std. Deviation } & \multicolumn{2}{c}{ Skewedness } & \multicolumn{2}{c}{ Kurtosis } \\
& Statistic & Statistic & Statistic & Statistic & Statistic & Statistic & Std. Error & Statistic & Std. Error \\
\hline cognitive & 100 & 32.00 & 70.00 & 52.8300 & 8.34491 & -.274 & .241 & -.349 & .478 \\
emotional & 100 & 32.00 & 71.00 & 53.7200 & 9.28894 & -.389 & .241 & -.336 & .478 \\
behavioural & 100 & 31.00 & 75.00 & 56.1100 & 8.90681 & -.513 & .241 & .078 & .478 \\
total attitude & 100 & 105.00 & 211.00 & 162.6600 & 23.97019 & -.343 & .241 & -.474 & .478 \\
\hline
\end{tabular}

As can be seen in Table15, the attitude scale and its subscales have a normal distribution, as the skewedness and kurtosis statistics are between -1 and +1 . A paired sample T-test was used to examine the difference between Iranian learners' attitudes towards English language prior to and after applying C-R activities and tasks. 
Table 16. A Paired Samples Statistics For Differences in Students' Attitudes Prior to and After Applying the $\mathrm{C}-\mathrm{R}$ activities and tasks

\begin{tabular}{|c|c|c|c|c|c|}
\hline & & Mean & $\mathrm{N}$ & Std. Deviation & Std. Error Mean \\
\hline \multirow{2}{*}{ Pair 1} & cognitive prior & 52.9574 & 47 & 7.26504 & 1.05971 \\
\hline & cognitive after & 53.1702 & 47 & 9.55606 & 1.39389 \\
\hline \multirow{2}{*}{ Pair 2} & Emotional prior & 53.8936 & 47 & 8.79781 & 1.28329 \\
\hline & Emotional after & 54.5532 & 47 & 9.25909 & 1.35058 \\
\hline \multirow{2}{*}{ Pair 3} & Behavioural prior & 56.5745 & 47 & 8.03185 & 1.17157 \\
\hline & Behavioural after & 56.6383 & 47 & 9.03237 & 1.31751 \\
\hline \multirow{2}{*}{ Pair 4} & General prior & 163.4255 & 47 & 21.52021 & 3.13904 \\
\hline & General after & 164.3617 & 47 & 25.47840 & 3.71641 \\
\hline
\end{tabular}

As can be seen in Table 16, the means of the attitude scale and its subscales prior to and after applying C-R activities and tasks are given for each group. It is clear from the obtained results that the differences are not much significant. To examine these results statistically, a paired-sample T-test was run. The results are given in Table 17.

Table 17. A Paired Samples t-test for Differences in the Participants' Attitudes Prior to and After Applying C-R activities and tasks

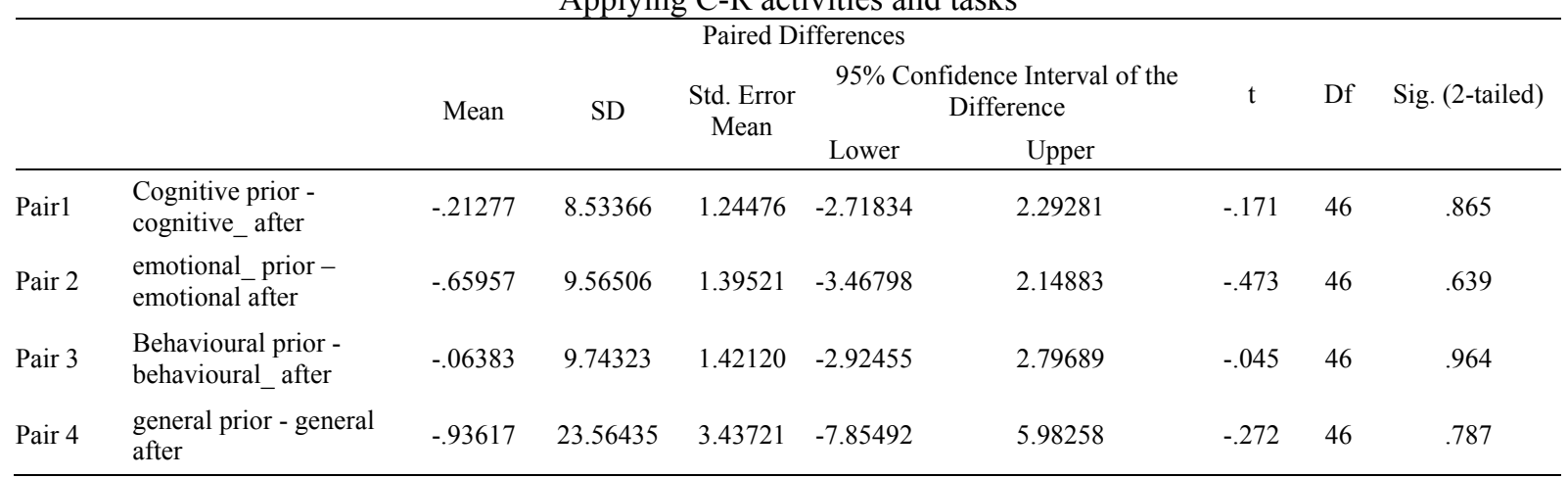

As shown in the table above, the general attitude scale and its subscales were not statistically significant. Therefore, applying C-R activities does not affect Iranian guidance school EFL learners' attitudes towards learning English language. Hence, the third null hypothesis is confirmed.

\section{Discussion of the Finding \\ Research arch Hypothesis 1:}

There is no significant difference between Iranian guidance school EFL learners learning grammatical structures through $C$ - $R$ activities and traditional methods?

The related research question is answered on the basis of the students' performance on pre-test and post-test of the grammatical structures. As it was mentioned before, participants' performance in the experimental group did show a significant development in learning grammatical structures namely the simple present tense. In other words, the results showed a significant difference between C-R activities and traditional approaches in terms of their effects on learning grammatical structures. The C-R approach led to a highly more improved knowledge of the grammar points (the simple present tense in this case) than its traditional counterpart. The findings obtained in this research led to the conclusion that there was a significant difference between the grammar means of the two groups allowing the researcher to reject the null first hypothesis. Therefore, this study supports the effectiveness of C-R activities and tasks in teaching grammar to EFL learners in Iranian guidance school. This study also suggests that implementing C-R activities and tasks can help learners to improve their knowledge of grammar. The results of the study run counter to the zero position advocated by Krashen. Krashen (1992) proscribed direct intervention and insisted that "the best way of increasing grammatical accuracy is comprehensible input and the most effective kind of comprehensible input for grammatical development is reading" (p. 411). 
These findings are in line with Mishan's (2005) argument that the rational of C-R approaches is that given sufficient exposure and opportunity, learners will discover elements of L2 grammar. In addition, the results of this study suggest that because of their important role in extracting and even explaining the grammar points in front of the class, students were all motivated in learning the grammar point which can lead to language acquisition. The result of this research also corroborates other similar studies. For example, Yip (1994) indicated the effectiveness of C-R in teaching ergative construction to EFL learners. Mohamed (2004), also, suggested that C-R tasks, both deductive and inductive, are effective learning tools and can therefore be used to raise learners' awareness of linguistic forms. Sugiharto (2006) contended that C-R is effective in helping students develop their explicit knowledge of the simple present tense. Moradkhan and Sohrabian (2009) argued that the use of C-R activities could be a very efficient technique in improving the grammatical knowledge of EFL learners. They believed that the combination of explicit and implicit learning can guide students towards language acquisition. The need for explicit rules can be more justified if it is embedded in communicative task. This study is not going to reject the role of other techniques in teaching grammar. The present research merely aimed to hold up the claim that the use of C-R activities and tasks in the classroom is a suitable technique in teaching grammar to EFL learners. It seems that it is better for the teacher to be aware of different techniques in teaching grammar and use them based on different circumstances. In Iran, learning grammar is one of the most important parts of learning English in the educational system.

\section{Research Hypothesis 2: \\ There is no significant difference between Iranian male and female guidance school EFL learners learning grammatical structures through $C-R$ activities and tasks?}

The second research question addressed the differences between males and females in both experimental groups. As it is mentioned before in, a significant difference was detected between males and females in the experimental groups. In other words, the findings did support the presumed difference between males and females in terms of their performance in grammar tests. In other words, the males outperformed the females in learning grammatical structures through $\mathrm{C}-\mathrm{R}$ activities and tasks. It is worth mentioning that since the sample size was not large enough and the participants were not selected randomly, and also since specialized raters were not available, the findings are not generalizable to all Iranian EFL learners. The results of this study are not compatible with Moradkhan and Sohrabian's (2009) study in which they reported that females had a better performance in learning grammatical structures through $\mathrm{C}-\mathrm{R}$ activities and tasks than males. Their study also supported the idea that the use of C-R activities and tasks can be effective for the purpose of developing accuracy rates of certain grammatical structures of intermediate female students. The main reason for the weak performance of female students in this study may be the fact that they were not familiar with the teacher's methodology in teaching and presentation of grammatical structures. Teachers should not be fanatical about one approach and deny the other ones since some grammar rules are not so easy to be discovered by students. Regardless to the approach to be effectuated, it should be subservient to the teacher's own consideration and orientation to decide what material to be introduced, to whom it should be given, and how it should be dealt with (Harmer, 1989). This, undoubtedly, is not an easy task, as it necessitates not only planning, but also complete understanding of course aims and the psychology of learners' needs, wants and situations.

\section{Research Hypothesis 3: \\ There is no significant difference between Iranian guidance school EFL learners' attitudes toward learning English language prior to and after applying C-R activities and tasks?}

The third question addressed the difference between Iranian guidance school EFL learners' attitudes towards learning English language prior to and after applying C-R activities and tasks. Based on the obtained results, the results of participants' attitude scale and its subscales prior to and after applying C-R activities were given for each group. Based on these results, the differences between the students' attitudes were not much significant. In other words, the difference between the participants' general attitude towards English language prior to and after applying C-R activities and tasks was not statistically significant ; therefore, applying C-R activities and tasks does not affect Iranian guidance school EFL learners' attitudes towards learning English language. Hence, the third null hypothesis was confirmed. The findings of this study proved that Iranian beginner learners showed neutral attitude towards learning English language prior to and after applying C-R activities. The results of this study confirm the results of Momani's (2009) study in which he found that Iranian attitudes towards learning 
English language are neutral. The findings of this study are not compatible with Al-Zahrani (2008), who reported that most of the Libyan participants in his study showed a negative attitude towards learning English language and it was also proposed that the reason of such a negative attitude might have been a reaction to the instructional and traditional techniques used by some of the English language teachers. The results of this study are not in consonant with Sham's (2008) study in which Iranian EFL learners showed a very positive attitude towards learning English language in their daily life. The findings of this study reject Shirbagi's (2010) findings that showed Iranian students had a positive attitude towards learning English language. And finally the results of this study are not in harmony with Vaezi's (2008) study in which Iranian EFL learners showed a very positive attitude and motivation towards learning English language. It's worth mentioning here that because of some misunderstandings on the part of the participants of this study, the limited number of the participants and lack of the expertise on the part of the researcher, the findings of this study cannot be generalized to all Iranian learners and different context. By the way, based on the researcher's experience as an English teacher in Iranian context the main reason for participants' neutral attitude refers to lack of expertise on the part of the instructors because they are not so knowledgeable enough to motivate the students try to learn the English language. Another reason refers to lack of exposure to language and its culture in Iranian context because English is considered as a foreign language in Iranian context.

\section{Conclusion and Suggestions for Further Research}

The present study was an attempt to investigate the effect of C-R grammar activities and tasks on Iranian guidance school EFL learners. The findings of the study suggested the superiority of C-R grammar tasks to pattern practice in promoting grammar knowledge in Iranian guidance school students. Since C-R activities and tasks for teaching grammar could be of various forms, future studies may investigate the effectiveness of various techniques such as highlighting, bolding, underlying and employing different colours that are available to language teachers for raising the consciousness of their students to grammar rules and other aspects of language. For future inquiry, although the present study was able to demonstrate how the C-R tasks successfully enhance L2 acquisition of the target grammar at beginner level, there was not adequate evidence to prove L2 enhancement of other aspects of language. A future study may replicate this present study in order to find out whether or not the findings of the future study agree with those of the present study. However, as it is pointed out by LarsenFreeman (2002), grammar is best conceived as encompassing three dimensions: form, meaning (content) and use. While productive practice may be useful for working on form, associative learning may account more for meaning, and awareness of and sensitivity to context may be required for appropriate use. Since grammar is complex, and students' learning styles vary, learning grammar is not likely to be accomplished through a single means of presenting it. Although practice has a role to play in language learning, Ellis (2002) maintains that it has a little value. He argues that the available evidence seems to suggest that practice, be it controlled, contextualized, or communicative, may not be as effective and useful as people claim it is. C-R, on the other hand, offers an attractive alternative to traditional grammar practice. Since C-R activities and tasks for teaching grammar could be of various forms, future studies may investigate the effectiveness of various techniques that are available to language teachers for raising the consciousness of their students to grammar rules. The respondents' obvious indifferent attitude toward learning English language may lead to conclude that they are not well aware of the importance of English and learn it as a compulsory subject. Briefly, the attitude concept is considered as an essential component in language learning. So, a positive attitude should be the umbrella of language learning. EFL teachers should respect, consider and think about their students' feelings, beliefs and behaviours before the cognitive abilities. English curriculum and classroom activities should involve affective aims according to the students' needs, wants, situations and their individual differences to build up positive attitudes toward learning English as a future must. Cognitive performance can be achieved if the EFL learners possess positive attitudes and enjoy acquiring the target language. For that reason, the affective perspective, especially attitude, should be considered in language research and should be valued at the beginning of language learning on the part of the teachers as the leading and effective factor in language acquisition process that can influence students' achievements greatly.Regarding the observed neutral attitude toward English, the EFL teachers are recommended to create an encouraging atmosphere in the English classes to promote the students' positive attitudes towards English. They should also motivate the students to learn English, highlighting its importance. This can be achieved by implementing the appropriate methods and activities of 
teaching English effectively. Furthermore, they should integrate up-to-date materials and supplementary resources in addition to the English text books. This can help them capture students' attention to learn English successfully. Moreover, the EFL teachers should consider the role of gender perspective in language learning, exposing various approaches to improve the students' attitudes, motivation and language performance as well. They are also recommended to teach the English curriculum as it is supposed to be taught, focusing on the communicative approach. The EFL teachers must be aware that communicative approach encourages EFL learners to collaborate and discuss their experiences and other issues regarding language learning. This can increase their attitude, enthusiasm and their motivation to acquire the language. Furthermore, curriculum makers should review the content and the design of the curriculum to meet the needs and the interests of the students. They are recommended to consider that the EFL learners have different perceptions about learning other languages due to their differences regarding gender, specialization, year of study, etc. Thus, taking all these issues into account, the curriculum design should be re evaluated so that students could see something different concerning the activities, content, topics, teaching practices etc. and be more motivated to learn English.

\section{Acknowledgement}

We wish to express our gratitude to students who participated in this study and answered the questions patiently, and we would also like to specially thank the Editor-in-Chief and the anonymous reviewer for their valuable and helpful comments and suggestions.

\section{References}

Alhmali, J. (2007). Student attitudes in the context of the curriculum in Libyan education in middle and high schools. PhD Thesis, University of Glasgow.

Al-Tamimi, A. \& Shuib, M. (2009). Motivation and attitudes towards learning English: A study of petroleum engineering undergraduates at Hadhramout University of Sciences and Technology. GEMA Online Journal of Language Studies.

Al-Zahrani, M. (2008). Saudi secondary school male students' attitudes towards English: An exploratory study. J. King Saudi University. Language and translation, pp.20, 25-39.

Baker, C. (1992). Attitudes and Language. Clevedon, England: Multilingual Matters.

.Brown, H. D. (2007).Teaching by Principles: An Interactive Approach to Language Pedagogy. New York: Pearson education.

Celce-Murcia, M. (1991). Grammar pedagogy in second and foreign language teaching, TESOL Quarterly, 25: 459-480.

Crivos, M. B \& Luchini, P. L. (2012). Pedagogical proposal for teaching grammar using consciousnessraising tasks. Published in MJAL 4:3 Autumn 2012.

De Bot, K. (2005). Second language acquisition: An advanced resource book. London: Routledge.

Ellis, R. (2002). Methodological options in grammar teaching materials. In E. Hinkel and S. Fotos (Eds.), New Perspectives on grammar teaching in second language classroom. Mahwah, NJ: Erlbaum Associates, pp.155-179.

Fasold, R. (1984). The sociolinguistics of society. Oxford: Blackwell.

Fortune, A. (1992). "Self-study grammar practice: learners' views and preferences." ELT Journal. 46(2): 160-171.

Fotos S, and Ellis, R. (1991). "Communicating about grammar: a task-based - approach". TESOL Quarterly. 25: 605-28.

Fotos, S. (1993). Consciousness through focus on form: Grammar task performance versus formal instruction. Applied Linguistics, 14: 385-407. 
Gardner, R. \& Lambert, W. (1972). Attitudes and motivation in second language learning. Rowley, Newbury House.

Gardner, R. (1985). Social psychology and second language learning: The role of attitudes and motivation. London: Edward Arnold.

Harmer, J. (1989), Teaching and Learning Grammar, Pearson Educational Limited, Longman, Bluestone Press, UK.

Krashen, S. (1992). Teaching issues: formal grammar instruction. TESOL Quarterly. 26: 406-411.

Larsen-Freeman, D. (1995). On the teaching and learning of grammar: challenging the myths. In Eckman et. al. (Eds).

Larsen-Freeman, D. (2002). Grammar. In R. Carter, \& D. Nunan, The Cambridge Guide to Teaching English to Speakers of Other Languages (pp. 39-40). Cambridge: Cambridge University Press.

Mishan, F. (2005).Designing Authenticity into Language Learning. Portland: Intellect Books.

Mohamed, N. (2004). Consciousness-raising tasks: a learner perspective. ELT Journal, pp.228-237.

Momani, M. (2009).The Jordanian Secondary Stage students Achievement in Reading Comprehension according to their views towards Learning English as a Foreign Language. Journal of Human Sciences, 42, pp.1-36.

Montano, D. E. \& Kasprzyk, D. (2008). Theory of reasoned action, theory of planned behavior, and the integrated behavioral model. In K. Glanz, B. Rimer \& K. Viswanath (Eds.), Health behavior and health education: Theory, research, and practice. San Francisco, CA: Jossey-Bass, pp. 6796.

Moradkhan, D. \& Sohrabian, R. (2009). Grammatical Consciousness-Raising Tasks and the Improvement of Iranian Students' Knowledge of Grammar. Journal of Teaching English as a Foreign Language and Literature, Islamic Azad University, North Tehran Branch, 1(4), pp.5771, fall 2009.

Larsen-Freeman, D. (1995). 'On the teaching and learning of grammar: challenging the myths' in Eckman et al. (eds.).

Padwick, A. (2010). Attitudes towards English and Varieties of English Globalizing India. University of Groningen. Newcastle, England. [Online] Available: http://scripties.let.eldoc.ub.rug.nl/FILES/root/Master/DoorstroomMasters/Euroculture/2009/a. m.j.padwick/MA-2802445-A.Padwick.pdf (August 9, 2011)

Prodromou, L. (1992). What culture? Which culture? Cross-cultural factors in language learning. ELT Journal, 46(1): 39-50.

Ranalli, J. M. (2001). Consciousness-raising versus deductive approaches to language instruction: a study of learner preferences .University of Birmingham.

Richards, J.C. \& T.S. Rodgers. (1986). Approaches and Methods in Language Teaching: A description and analysis. Cambridge: Cambridge University Press.

Shams, M. (2008).Students' attitudes, motivation and anxiety towards English language learning. Journal of Research, 2(2): 121-144.

Sharwood Smith, M. (1993).Input Enhancement in Instructed SLA. Studies in Second Language Acquisition 15: pp. 165-179.

Shirbagi, N. (2010). Orientations and attitudes Of Iranian University Students for English Language Learning. PEDAGOGIKA. 2010. p. 99 
Sugiharto, S. (2006). Consciousness-raising and the acquisition of the simple present tense rule. Paper presented at the sixth Malaysia International Conference on English Language Teaching (MICELT), Equatorial Hotel, Melaka, Malaysia, May pp.8-10.

Thornbury, S. (1999) How to Teach Grammar. Harlow: Longman.

Vaezi, Z. (2008). Language learning motivation among Iranian undergraduate students. World Applied Sciences Journal, 5(1): 54-61.

Yip, V. (1994). Grammatical Consciousness-raising and Learnability. In T. Odlin, Perspective on Pedagogical Grammar pp. 123-139. Cambridge: Cambridge University Press. 